\title{
“ANTIGAMENTE NÃO TINHA ISSO NÃO!": CRIMINALIDADE, MIGRAÇÕES E A RESSIGNIFICAÇÃO DO RURAL NA ZONA DA MATA MINEIRA
}

\author{
"¡EN EL PASADO, ESO NO EXISTÍA!": DELINCUENCIA, MIGRACIÓN Y LA RESIGNIFICACIÓN DE LO RURAL EN LA ZONA \\ DE LA MATA MINERA.
}

\section{RESUMO}

Introdução: O desenvolvimento rural possibilitado pela modernização da agricultura agregou diversos resultados positivos para o campo, como a utilização de tecnologia, melhorias na qualidade de transporte e infraestrutura, ainda que sua distribuição tenha sido desigual. No entanto, o campo, há décadas representado como lugar tranquilo e pacífico, começa a se tornar um espaço propício a determinadas práticas criminais até então consideradas tipicamente urbanas. Objetivo: Pretende-se com este trabalho analisar se o aumento da criminalidade no campo vem modificando as representações sociais sobre o espaço rural e influenciando projetos familiares de deslocamento espacial e abandono das atividades agropecuárias. Metodologia: A metodologia consiste em pesquisa documental e de campo, com aplicação de questionários e entrevistas com famílias rurais. Resultados: Os resultados apontam que há uma relação entre a descontinuidade da atividade agropecuária e o aumento da criminalidade do meio rural, pois roubos e furtos têm como principal alvo idosos e pequenas propriedades familiares. Fatores apresentados como favoráveis para a ocorrência desses crimes é a facilidade de fuga e o baixo policiamento nessas localidades.

Palavras-chave: Desenvolvimento rural. Segurança Pública. Deslocamentos Populacionais.

\section{RESUMEN}

Introducción: El desarrollo rural derivado de la modernización de la agricultura agregó varios resultados positivos para el campo, como el uso de tecnología, mejoras en la calidad del transporte y la infraestructura, a pesar de que su distribución ha sido desigual. Sin embargo, el campo que durante décadas ha representado un lugar tranquilo y pacífico, comienza a convertirse en un espacio propicio para ciertas prácticas criminales que eran consideradas típicamente urbanas.Objetivo: Este trabajo tiene como objetivo analizar si el aumento de la delincuencia en el campo ha modificado las representaciones sociales sobre el espacio rural y si ha influido en proyectos familiares de desplazamiento y abandono de las actividades agropecuarias. Metodología: La metodología consiste en investigación documental y de campo, con la aplicación de cuestionarios y realización de entrevistas a familias rurales. Resultados: Los resultados muestran que existe una relación entre la discontinuidad de la actividad agrícola y el aumento de la delincuencia en las zonas rurales, ya que los robos se cometen principalmente a personas en la etapa de vejez y en pequeñas propiedades familiares. Los factores encontrados como favorables para la ejecución de estos crímenes son la facilidad de escape y la baja vigilancia en estos lugares.

Palabras-clave: Desarrollo rural; seguridad públic; desplazamientos de población

\author{
João Paulo Louzada Vieira ${ }^{a}$ \\ Dheila Maria Doula ${ }^{a}$ \\ D Marco Paulo Andrade ${ }^{a}$ \\ (D) Isadora Moreira Ribeiro ${ }^{a}$ \\ (D) Jeferson Henrique dos Reis \\ Lopes $^{a}$ \\ a Universidade Federal de Viçosa \\ (UFV),Viçosa,MG, Brasil
}

DOI: 10.12957/geouerj.2021.43841

Correspondência:

marcopandrade@yahoo.com.br

Recebido em: 8 jul. 2019

Aceito em: 7 out.2020 


\section{INTRODUÇÃO}

O presente artigo surgiu das inquietações dos pesquisadores ao realizarem pesquisas de campo para a coleta de dados do projeto Lugares de saída, lugares de chegada: caminhos e reconfigurações simbólicas da mobilidade socioespacial entre jovens rurais da Zona da Mata Mineira" ${ }^{\prime 1}$. Corriqueiramente os entrevistados apresentavam o aumento da criminalidade e da violência nos espaços rurais como um fator que, na atualidade, vem dificultando a permanência das famílias em suas propriedades e colaborando para projetos familiares de deslocamento espacial rumo às cidades.

É fato que entre os anos de 2014 e 2018 houve uma proliferação de reportagens sobre o aumento da criminalidade no campo. Diversos canais televisivos, jornais e sites de notícias como "Globo rural", "Band News" e "Folha de São Paulo" passaram a dar visibilidade ao assunto, representando-o como um novo problema social no meio rural.

Se por um lado a mídia vem exercendo um papel de extrema importância, chamando a atenção dos órgãos governamentais e instituições ligadas tanto ao agronegócio quanto à segurança pública, buscando uma possível solução para o problema, por outro também se verifica que o tema "segurança no campo" passou a fazer parte das principais pautas debatidas pelos candidatos à Presidência da República no ano de 2018.

É importante destacar que criminalidade e violência no meio rural não são fenômenos atuais e, apesar de incorporarem novas configurações de delitos, sempre houve na história do Brasil práticas ligadas ao "sistema costumeiro", que se materializou desde o período colonial.

Da colonização à contemporaneidade, diversos tipos criminais e atos de crueldade se consolidaram em todo território nacional. Capangas, coronéis, jagunços, grileiros, cangaceiros são personagens de destaque nesse cenário de brutalidade (FRANCO, 1983; GUIMARÃES, 1981, FACÓ, 1991; HOBSBAWN, 1976; DEL PRIORE e VENÂNCIO, 2006).

Dados históricos mostram a ação de saqueadores que atuavam nas rotas do comércio e nos roubos em fazendas (DEL PRIORE e VENÂNCIO, 2006). Sobre os saqueadores, em alguns momentos na história, ocorre o fenômeno chamado de "banditismo social" (HOBSBAWN, 1976), no qual estes sujeitos tornam-se heróis e os atos violentos e criminosos são justificados como necessários na busca por reduzir as desigualdades sociais.

Um exemplo clássico do "banditismo social" no Brasil encontra-se na figura do cangaceiro Lampião, que roubava fazendas de pessoas com alto poder aquisitivo e distribuía aos pobres do sertão nordestino. Existem, também, relatos que mostram que Lampião e seu bando eram contratados para proteger as fazendas de outros saqueadores (HOBSBAW, 1976; DEL PRIORE e VENÂNCIO, 2006).

\footnotetext{
${ }^{1}$ Projeto financiado pela Fundação de Amparo à Pesquisa do Estado de Minas Gerais - FAPEMIG
} 
Além do baditismo, os chamados "códigos de hora ou código do sertão" são atos criminosos e violentos comumente praticados nas regiões rurais, em situações onde a honra e a masculidade encontram-se em disputa. São crimes violentos, envolvendo meios de execução brutais utilizando-se de armas brancas ou ferramentas de trabalho, ocasionados por motivos "banais" e que ocorrem entre vizinhos e indivíduos com algum grau de parentesco (FRANCO, 1993; FELIX, 2002; ZALUAR, A.; NORONHA, J. C. \& ALBUQUERQUE, 1994, p. 215).

Alimentada por um sistema de subordinação, violência e poder, a capangagem marcou o rural brasileiro durante o seculo XIX. A mando dos patrões os capangas coagiam a população a trabalhar nas fazendas, defender a honra do seu senhorio em disputas territoriais e votar em candidatos políticos apoiados por eles (GUIMARÃES, 1981). Outra figura que se destacou pelo uso da violência e valentia foi o jagunço, conhecido popularmente como "cabra, guarda-costas, capanga, mumbava” (QUEIROZ, 1976, p. 219). O estabelecimento desse personagem na história brasileira se deu com o avanço do capitalismo impulsionado pela agricultura latifundiária, principalmente na região amazônica, onde a violência era empregada como meio coercitivo àqueles que viessem a contrariar os interesses latifundiários (GUIMARÃES, 1981). Esses personagens atendiam aos interesses daqueles que detinham os meios de produção e, apesar de "seguirem as leis", praticavam crimes por lealdade e (ou) em troca de dinheiro(QUEIROZ, 1976). Na disputa por terra, a mando dos coronéis os capangas e jagunços matavam e torturavam.

As disputas por terra e pela exploração do meio ambiente também são fatores que contribuem para que os conflitos em áreas rurais perdurem até o presente. Desde a década de 1980, diversas Unidades da Federação registraram conflitos que ficaram conhecidos no senso comum como massacres ${ }^{2}$, devido ao grande número de mortos contabilizados e pelos episódios de violência e brutalidade praticados.

Os conflitos agrários e socioambientais tornam-se cada vez mais parte da realidade brasileira. Com intuito dar visibilidade a esses conflitos, a Comissão Pastoral da Terra, a partir do ano de 2017, começou a mapear e divulgar os massacres ocorridos nas últimas três décadas no meio rural, em diversas regiões brasileiras. Entre os anos de 1985 e 2017 foi mapeado um total de 47 conflitos, sendo 26 deles no Estado do Pará, região que possui grandes extensões de matas nativas e desperta o interesse da agricultura latifundiária, madeireiros e empresas internacionais de fármacos (CPT, 2017).

Em 2017 foram registrados cerca 71casos de assassinatos isolados no meio rural (praticamente o dobro em comparação com o ano de 2014), aproximadamente 120 tentativas de homicídios a cada três dias, 226 ameaças de morte, 137 agressões, 6 pessoas torturadas e 263 pessoas presas (CPT, 2017). Também foram

${ }^{2} \mathrm{O}$ termo massacre utilizado pela CPT corresponde a assassinatos onde o número de vítimas é maior ou igual a 3 pessoas. 
realizados ataques contra servidores do Instituto Brasileiro do Meio Ambiente e dos Recursos Naturais Renováveis (IBAMA) e do Instituto Chico Mendes de Conservação da Biodiversidade (ICMBio).

Dois casos de assassinatos que ficaram internacionalmente conhecidos e ganharam grande repercussão ocasionados pelos conflitos agrários e socioambientais foram o da missionária Doroty Stang, assassinada em 2005 no Município de Anapu, no Estado do Pará, e do ativista e líder de movimentos sociais Chico Mendes, assassinado em 1988 no Município de Xarupu, no Estado do Acre.

$\mathrm{Na}$ atualidade, destaca-se que a criminalidade no espaço rural vem apresentando outras configurações para além dos conflitos agrários e ambientais. Nos fluxos entre o campo e cidade, crimes como roubos, furtos, estupros, sequestros, assassinatos, ataques a agências bancárias e narcotráfico cada vez mais se tornam parte do cotidiano rural e modificam os hábitos das pessoas, afetando a economia local, aterrorizando a população e alterando seus meios de vida.

O processo de urbanização e modernização trouxe diversas contribuições para o campo, como o melhoramento de maquinários, meios de comunicação e novas tecnologias da informação, implementação de atividades não agrícolas, acesso aos meios de transportes, bem como o aumento do número de cidades no interior e o crescimento das taxas de população urbana em relação à população rural. Entretanto, esse desenvolvimento não veio acompanhado de políticas de segurança pública, o que contribuiu para explicar a percepção sobre o aumento da criminalidade em áreas vulneráveis do interior.

A partir do exposto acima, o presente artigo tem por objetivo analisar se o aumento da criminalidade vem modificando as representações sociais sobre o espaço rural e influenciando projetos familiares de deslocamento espacial e abandono das atividades agropecuárias. A pesquisa foi realizada em municípios da Zona da Mata Mineira.

\section{A CRIMINALIDADE NA ZONA RURAL BRASILEIRA}

Atualmente tem se tornado de uso comum a tese da "interiorização da criminalidade (ANDRADE e DINIZ, 2013), fortalecida pela contabilização do aumento nos números de vítimas no setor agropecuário e nas zonas rurais do país. Esse "novo" panorama causado pela criminalidade vem chamando a atenção dos veículos de comunicação e mobilizando instituições públicas e privadas (principalmente aquelas ligadas ao meio rural) a planejarem formas de combate e redução da criminalidade no campo, segundo a tese da "interiorização":

Estamos diante de novos fenômenos da criminalidade moderna, e da violência que dela faz parte, muito diferente da violência costumeira dos sertões brasileiros, onde imperavam um código de honra muito claro e conflitos interfamiliares agudos, num quadro de fraqueza institucional (ZALUAR, A.; NORONHA, J. C. \& ALBUQUERQUE, 1994, p. 215). 
Em 2018, a redistribuição espacial da criminalidade e sua intensificação nas zonas rurais tornou-se um dos principais debates das agendas de campanha dos presidenciáveis, tendo como principal proposta o porte rural de arma de fogo, que visa desburocratizar o acesso para os produtores rurais e residentes no campo, o que pode se concretizar em 2019.

Outra proposta foi começar a mensurar o fenômeno a partir de análises estatísticas. Buscando dar maior visibilidade ao problema e chamar a atenção das Secretarias de Segurança Pública, a Confederação da Agricultura e Pecuária (CNA) criou o Observatório da Criminalidade no Campo no ano de 2017, que consiste em uma ferramenta eletrônica hospedada no próprio site $^{3}$ da entidade e que permite a produtores, trabalhadores rurais e residentes no campo relatarem ocorrências em suas propriedades, de modo a contribuir para a realização de um diagnóstico mais preciso.

Segundo a CNA (2018), o PIB do agronegócio encerrou o ano de 2017 com um total de 21,7\% do PIB nacional, sendo que $32,3 \%$ da classe trabalhadora brasileira está vinculada a esse setor. Além disso, o Brasil registrou no período que corresponde de janeiro a março de 2018 um total de 36\%, alcançado somente pelo agronegócio de toda a exportação brasileira. Ressalta a entidade, fazendo um alerta, que apesar de todo esse progresso no campo, o setor encontra-se ameaçado pela falta de segurança pública e pela vulnerabilidade dos produtores e trabalhadores rurais (CNA, 2018). No mesmo sentido, o jornal O Estado de São Paulo divulgou uma matéria contabilizando os ganhos econômicos do agronegócio relacionados com o aumento da criminalidade no campo nos últimos 4 anos.

De acordo com os dados oficiais disponibilizados ao jornal O Estado de São Paulo pelas Secretarias de Segurança Públicas estaduais, bem como pelo Centro de Estudos Avançados em Economia Aplicada (CEPEA), Confederação da Agricultura e Pecuária (CNA) e Instituto Brasileiro de Geografia e Estatística (IBGE), os índices de criminalidade no campo vêm aumentando gradativamente nos últimos anos. Somente no Estado do Mato Grosso os dados apontam para um aumento de $60 \%$ envolvendo os crimes de furto e roubo entre os anos de 2014 e 2017. O estado de Goiás também é destacado nessa estatística, com aumento de $20 \%$, seguido com 7,5\% pelo Rio Grande do Sul, e Minas Gerais com o total de 4\%, sendo que este estado contabilizou aproximadamente 139 casos por dia nos últimos 2 anos (Figura 1).

${ }^{3}$ Site da CNA - http://www.cnabrasil.org.br/ 
Figura 1. Balanço da criminalidade nas zonas rurais brasileiras. Fonte: O Estado de São Paulo, 06/05/184.

\section{VIOLÊNCIA NO CAMPO}

- Estatísticas de crimes na zona rural

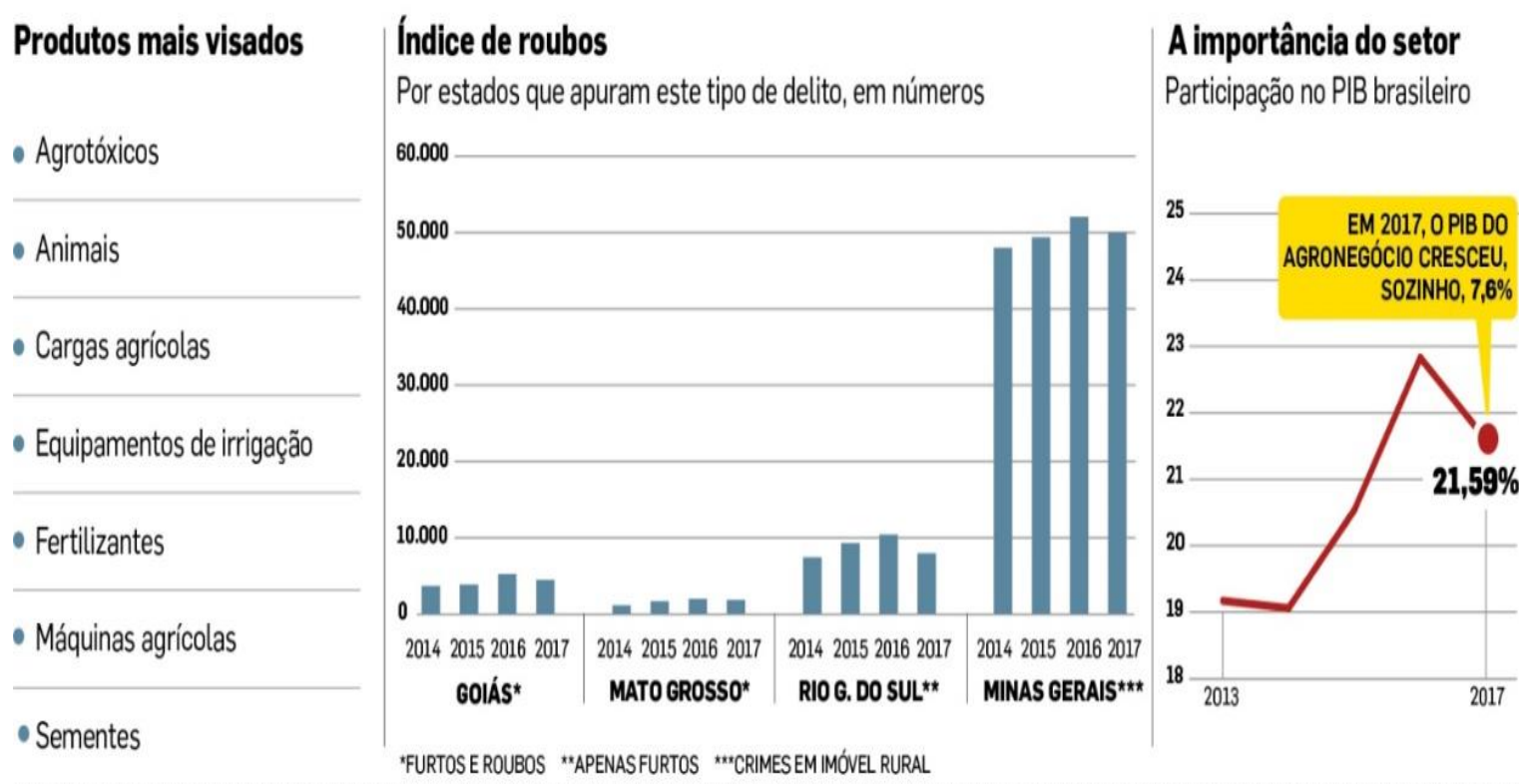

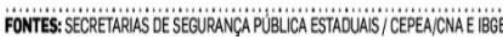

Conforme o infográfico, entre os produtos mais visados nos casos de furto e roubo estão: agrotóxicos, animais, cargas agrícolas, equipamentos de irrigação, fertilizantes, máquinas agrícolas, sementes etc. Todos esses produtos são dotados de alto valor monetário e possuem um destinatário específico ("desmanche" de peças, por exemplo).

O abigeato (furto e roubo de animais, mesmo que abatido em partes) é um tipo criminal quem vem sendo muito praticado no Brasil, principalmente nas regiões fronteiriças com países da América do Sul, contribuindo com o crescimento do mercado ilegal de carnes:

O abigeato, que consiste no roubo - há casos de assalto à mão armada às propriedades na Fronteira Sul do Brasil e mesmo no Uruguai - ou no furto de animais (os casos mais frequentes), tem consequências econômicas e sociais importantes. Provê alimento a baixo custo ou a custo zero para importantes contingentes, mas, de outra parte, causa prejuízos econômicos aos proprietários dos animais (dos bovinos ou ovinos), contribui para um mercado clandestino, inclusive com um contrabando de couros e peles, põe em riso a saúde dos consumidores e traz danos aos cofres públicos por constituir instrumento de evasão fiscal (MELO, 2004, P. 139).

${ }^{4}$ Infográfico disponibilizado e autorizado para uso pelo jornal O Estado de São Paulo. 
A CNA também realizou um balanço geral da criminalidade a partir dos registros no Observatório da Criminalidade no Campo. Segundo os dados disponibilizados na cartilha "Diagnósticos da criminalidade no campo", essa ferramenta vem permitindo a realização de um mapeamento dos principais crimes praticados nas zonas rurais. Assim, contabilizou-se no ano de 2017 um total 149 ocorrências, sendo que 50\% correspondem ao furto, 32 \% ao roubo, 12 \% de depredação e $3 \%$ à queima e assassinato (Figura 2 ).

Figura 2. Tipos de ocorrência criminal no campo. Fonte: Observatório da Criminalidade no Campo (CNA) $-2017^{5}$.

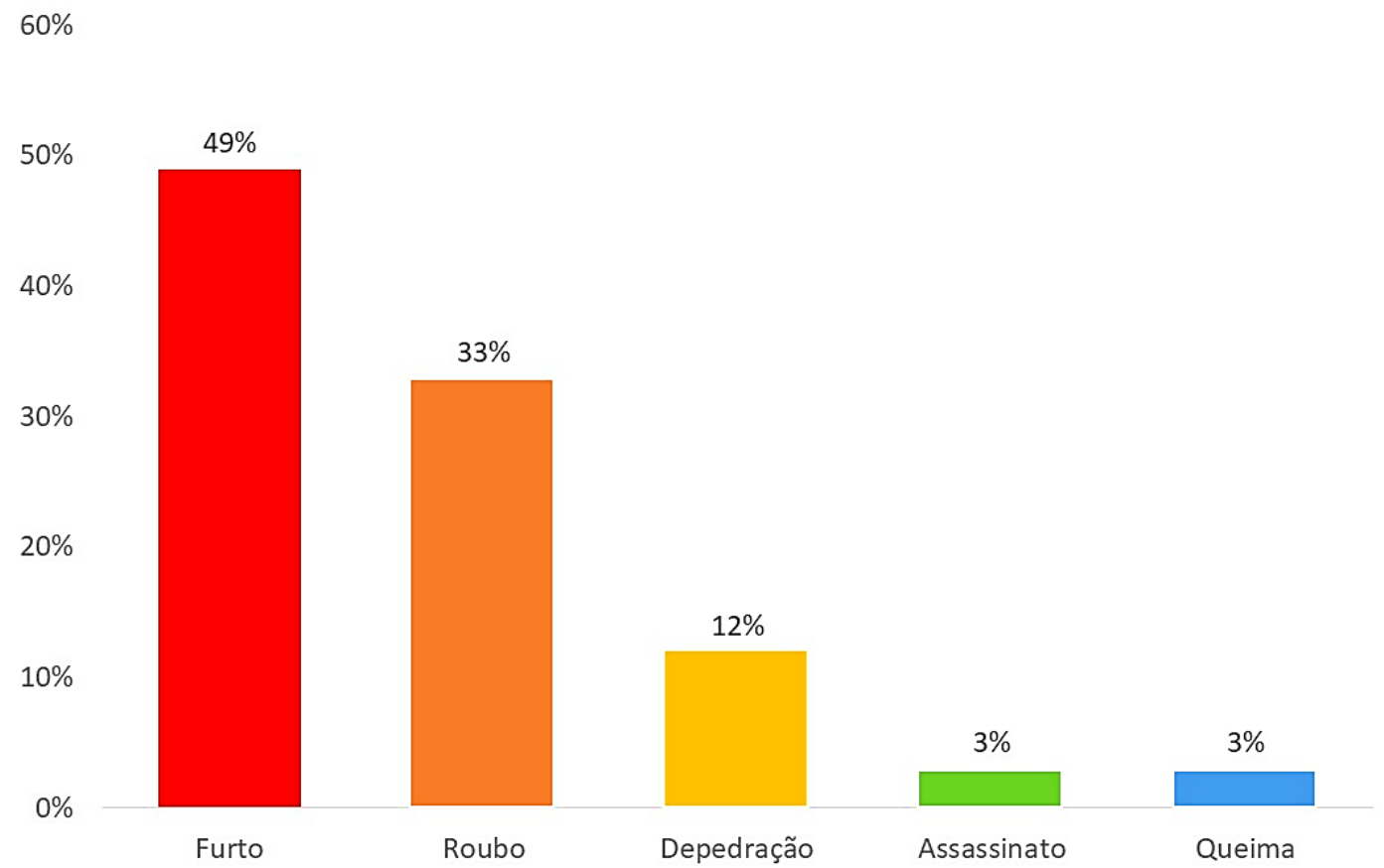

Esses registros são apenas uma amostra da criminalidade nas zonas rurais brasileiras, pois grande parte das vítimas deixa de realizar o Boletim de Ocorrência junto aos órgãos policiais, contribuindo para o aumento da "cifra negra" e para inviabilizar os trabalhos de segurança pública (GIDDENS, 2008). Tal invisibilidade pode se justificar também pela distância entre a propriedade rural e a sede do Município mais próximo, onde se localizam os órgãos policiais.

O valor do objeto ou a descrença na atividade policial pode também estar diretamente relacionado com a realização ou não do Boletim de Ocorrência:

A principal limitação das estatísticas oficiais sobre o crime reside no fato de apenas incluírem os crimes participados à polícia. Há uma longa cadeia de decisões problemáticas entre um possível crime e o seu registo pela polícia. A maioria dos crimes, especialmente os pequenos roubos, nunca chegam a ser comunicados à polícia (GIDDENS, 2008, p.219).

\footnotetext{
${ }^{5}$ Os dados e gráficos foram enviados por e-mail pelo CNA com autorização para seu uso.
} 
É importante destacar que não só grandes pecuaristas e agricultores patronais são vítimas da criminalidade no campo. Regiões com baixo nível de desenvolvimento econômico e populações de pequenos proprietários e agricultores familiares também vêm sofrendo com esse problema, como é o caso da região focalizada neste artigo.

\section{METODOLOGIA}

A pesquisa de cunho exploratório utilizou como recursos métodológicos a pesquisa documental, aplicação de questionários e entrevistas (LAKATOS e MARCONI, 2001), com intuito de compreender como os fenômenos da criminalidade influenciam as representações sociais sobre o espaço rural e sobre a permanência nesse espaço.

Os documentos analisados foram reportagens apresentadas nos jornais regionais Folha da Mata e Viçosa Urgente (Online) e O Estado de São Paulo. Também foram utilizados documentos disponibilizados pelo instituto da Confederação da Agricultura e Pecuária do Brasil - CNA. Dos jornais Folha da Mata e Viçosa Urgente (Online) analisou-se um total de 175 notícias divulgadas sobre criminalidade em nível regional e local, no período de janeiro de 2014 a dezembro 2018.

Ainda como etapa da pesquisa documental, foram utilizadas informações do Centro Integrado de Defesa Civil (CINDS) da Secretaria de Estado de Segurança Pública (SESP-MG), disponibilizadas em CD à equipe de pesquisadores. Dessas informações foram extraídas as ocorrências constatadas no meio rural mineiro no período de 2014 a 2018.

As entrevistas foram realizadas com moradores de áreas rurais dos Municípios de Divinésia, Dores do Turvo, Visconde do Rio Branco, Cajuri, Paula Cândido, São Geraldo, São Miguel do Anta e Ubá, todos pertencentes à Zona da Mata Mineira (figura 3). Participaram das entrevistas 15 pessoas, 13 homens e 2 mulheres, com idades entre 22 e 62 anos. Todos apresentam características bastante semelhantes, com origem familiar rural, são pequenos proprietários e em algum momento da vida migraram para o meio urbano. Ressalta-se que os jovens (73) participantes desta pesquisa são estudantes universitários. Entre os mais velhos, percebe-se menor nível de escolaridade, sendo que grande parte não concluiu o ensino fundamental. 
Figura 3. Municípios onde foram realizadas as entrevistas. Fonte: Elaborado pelos autores.

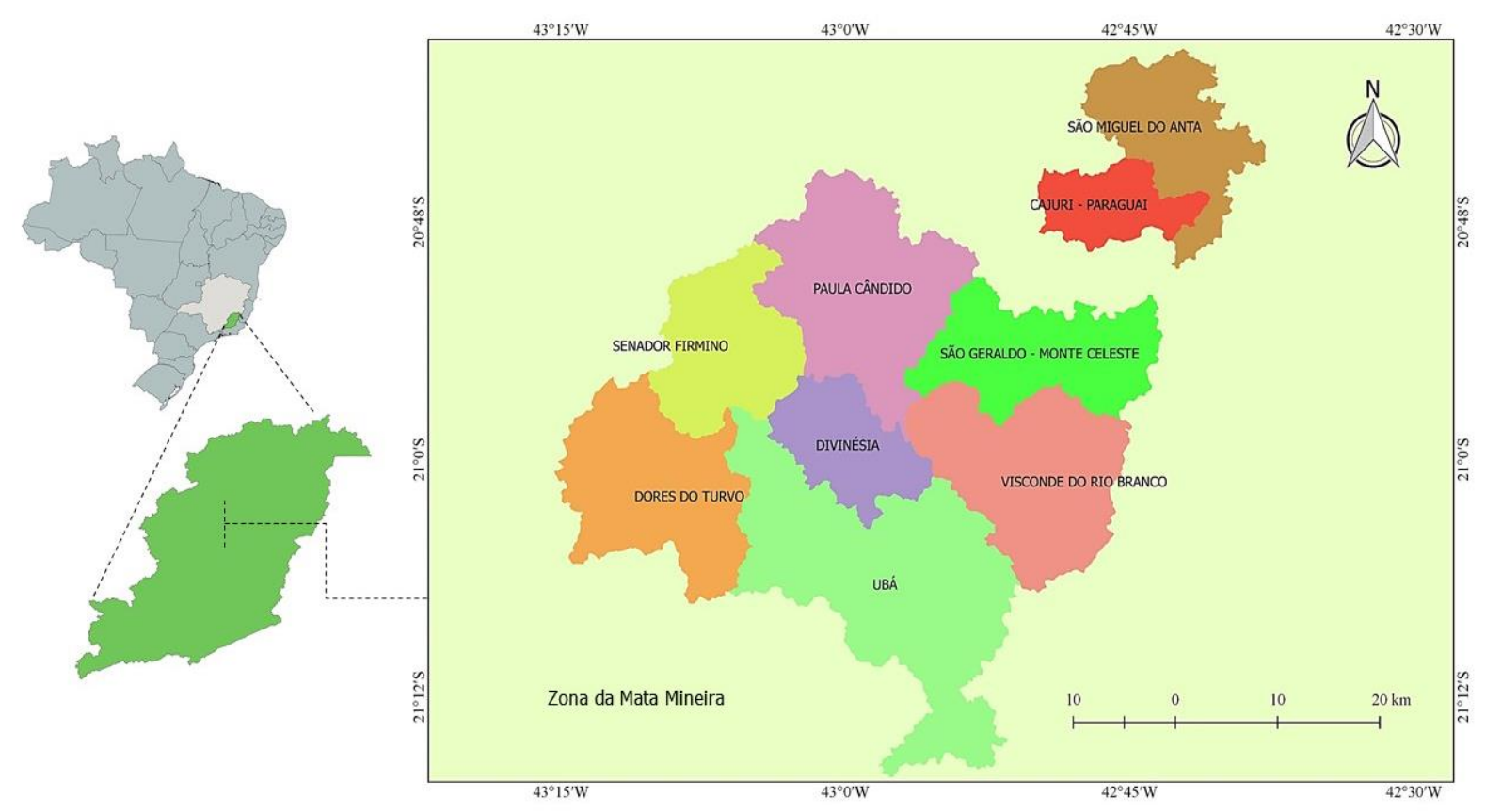

Os entrevistados foram selecionados aleatoriamente, sendo abordados nas intermediações de suas propriedades, apresentados à pesquisa e convidados a participar. Com intuito de preservar as identidades das/o informantes iremos nos referir a eles como E1, E2, E3 etc. As informações dos documentos, questionários e entrevistas foram organizadas e sistematizadas. Posteriormente realizou-se a análise de conteúdo (LAKATOS e MARCONI, 2001).

Em relação às questões éticas, o projeto, "Como é que a gente fica no campo desse jeito?" os impactos da criminalidade e da violência no campo - microrregião de Viçosa-MG, foi submetido e aprovado pelo Comitê de Ética em Pesquisa com Seres Humanos da Universidade Federal de Viçosa, obedecendo as recomendações da Resolução n. 466/2012 do Conselho Nacional de Saúde do Ministério da Saúde (CNS/MS), de 12 de dezembro de 2012, obtendo o parecer no 2.955.804. O Termo de Consentimento Livre e Esclarecido foi dirigido a todos os participantes, que autorizaram, a gravação das entrevistas e a divulgação dos resultados.

\section{RESULTADOS E DISCUSSÕES}

A criminalidade rural na Zona da Mata mineira

Conforme pôde-se perceber na sessão anterior, nos últimos quatro anos o Estado de Minas Gerais contabilizou um grande número de ocorrências criminais no campo. Segundo os dados do Centro Integrado de Defesa Social (CINDS) - Secretaria de Estado de Segurança Pública - SESP, houve um total de 130.466 (cento e trinta 
mil, quatrocentos e sessenta e seis) Registros de Eventos de Defesa Social (REDS) em áreas rurais de todo o estado no período de janeiro de 2014 a dezembro de 2018 (Tabela 1).

Tabela 1. Números de Registos de Eventos de Defesa Social (REDS) em áreas rurais do Estado de Minas Gerais - 2014 a 2018. Fonte: Elaborado pelos autores com base nos dados do Centro Integrado de Defesa Social (CINDS) - Secretaria de Estado de Segurança Pública - SESP-MG.

\begin{tabular}{lll}
\hline Natureza & Número de registros & Taxa das Ocorrências (\%) \\
\hline Furto & 118.185 & 90,6 \\
Roubo & 8.370 & 6,4 \\
Estupro e Estupro de Vulnerável & 1.754 & 1,3 \\
Homicídio Consumado & 1.295 & 1,0 \\
Homicídio Tentado & 862 & 0,7 \\
Total & $\mathbf{1 3 0 . 4 6 6}$ & $\mathbf{1 0 0}$ \\
\hline
\end{tabular}

Os dados da tabela 1 poderiam apresentar um resultado ainda maior se fossem contabilizadas as ocorrências que não estão registradas, notadamente de furto e roubo, quando o valor do objeto é considerado pequeno pelas vítimas.

Especificamente na Zona da Mata Mineira, ao se considerar as matérias jornalísticas, os resultados apontam um aumento significativo na frequência das ocorrências. A análise das reportagens retrata uma curva crescente da prática criminal nos espaços rurais da região e o setor midiático passou a monitorar com maior frequência esses registros. O ano de 2014, ponto inicial dessa análise, contabilizou 8 notícias. De 2014 a 2018 vê-se a intensificação de reportagens, tendo este último ano 62 notícias divulgadas. Vale ressaltar que nem todos os casos em áreas rurais são noticiados pela mídia (Tabela 2) e que as notícias se baseiam nos Boletins de Ocorrência registrados pelas vítimas e seus familiares.

Tabela 2. Número de reportagens divulgadas sobre a criminalidade em áreas rurais na Zona da Mata Mineira. Fonte: Elaborado pelos autores com base nas notícias divulgadas no Viçosa urgente (online) -2018.

\begin{tabular}{ll}
\hline Ano & Reportagens \\
\hline 2014 & 8 \\
2015 & 30 \\
2016 & 27 \\
2017 & 47 \\
2018 & 62 \\
Total & 154 \\
\hline
\end{tabular}


Nas reportagens analisadas, 29\% apresentavam ação da polícia na captura e identificação do suspeito. Os textos apresentam crimes de homicídios e roubo que ainda não foram solucionados, dando ênfase ao trabalho investigativo da polícia. Tais reportagens enfatizam a importância das denúncias para que o crime seja solucionado.

As reportagens apresentam o baixo policiamento e a facilidade de fuga em estradas vicinais como fatores que favorecem o aumento de crimes no espaço rural, sendo a motocicleta apontada como o veículo automotivo mais utilizado para este fim. As notícias apontam as motocicletas e carros roubados/furtados como veículos utilizados para cometer delitos em outras localidades. Sobre os roubos e furtos, $27 \%$ das notícias reportam a ação efetiva da polícia na busca e apreensão dos produtos.

Os dados apontam roubo e furto ${ }^{6}$ como crimes praticados com maior frequência, $51 \%$. As reportagens apresentam os idosos e aposentados como principais vítimas. Coincidência ou não, evidencia-se que a maioria dos crimes noticiados acontece entre os meses de novembro e dezembro (26\%), período em que o décimo terceiro salário começa a ser pago. Além disso, as notícias identificam as propriedades isoladas, que não possuem caseiro e sem a presença da família, como locais de maior incidência de furto de gado, ferramentas, máquinas agrícolas e fios de cobre.

O segundo tipo de crime mais praticado é o homicídio, que ocorre tanto no roubo seguido de morte (latrocínio), quanto por desavenças em bares, acertos de conta e dívida com o tráfico de drogas. As reportagens destacam a violência contra a mulher, com seis matérias que noticiam o feminicídio, e 7 que abordam tentativas de estupro e estupro consumado.

Outros delitos como tráfico de drogas e porte ilegal de armas também são noticiados. As narrativas jornalísticas apontam a zona rural sendo utilizada como esconderijo de drogas, acompanhando o noticiário nacional que veicula que, por falta de policiamento, as pequenas estradas do interior têm se convertido em espaço de descarte de veículos roubados e mesmo de corpos de vítimas.

Sobre o perfil dos criminosos, $15 \%$ das notícias indicam que são em sua maioria moradores das áreas urbanas que se deslocam para a zona rural com o intuito de cometer o delito. São caraterizados como pessoas de porte físico magro, tatuado, trajando tênis, bermuda e blusa com capuz. A idade dos criminosos não se encontra em todas as notícias, entretanto, evidencia-se que roubos e furtos são praticados em sua maioria por indivíduos entre 16 e 30 anos e os homicídios, na maioria das vezes, por indivíduos com 30 anos ou mais.

\footnotetext{
${ }^{6}$ De acordo com o Código Penal Brasileiro, instituído pelo Decreto Lei no 2.848, de 7 de dezembro de 1940 , considera-se furto a subtração para si ou para terceiros a subtração de coisa alheia móvel. Quando esta é realizada mediante o emprego de grave ameaça ou violência caracteriza-se crime de roubo.
} 
Em relação às entrevistas, ao questionarmos os participantes sobre a criminalidade no campo, um entrevistado se recusou a responder argumentando "não ser bom falar sobre crimes". O silêncio tem muito a dizer e a excitação em falar resulta do medo às represálias por parte dos criminosos. Partindo dessa premissa, podemos inferir que os criminosos podem não ser estritamente citadinos e é possível que sejam conhecidos da população local. Esse dado permite questionar o argumento de que criminosos estariam migrando dos grandes centros urbanos para o meio rural e sugerir, ao contrário, que certos tipos de crimes passam a ser cometidos por indivíduos das próprias vizinhanças, daí o receio de identificá-los publicamente.

Os demais entrevistados não se opuseram a falar sobre os crimes e afirmam que percebem um aumento dessas práticas, principalmente por parte de jovens do sexo masculino, usuários de drogas que se "deslocam da cidade para o campo". Os perfis dos criminosos assemelham-se ao apresentado nas reportagens e ao observado nos estudos desenvolvidos por Sapori e Soares (2015), Pimenta (2014), e Giddens (2008). Também há a percepção de que os criminosos estão se associando em quadrilhas com especialidade em cometimento de crime nas zonas rurais:

Aqui na roça tem muito roubo, teve um tempo que tinha uma quadrilha roubando nas casas por aí à fora, é muito lugar que a gente sabe (E4).

Na zona rural isso tem se tornado cada vez mais comum, então eu não sei dizer o número certo de pessoas, mas isso vêm se tornando comum, em constante aumento (E1).

Os tipos de atividades criminosas mais citadas pelos entrevistados são roubo e assassinato. Os roubos geralmente acontecem em pequenos mercados dos municípios e nas propriedades rurais. Dentre os objetos mais visados estão veículos automotivos - principalmente as motos - sacas de café, saco de ração e gado. No que se refere aos assassinatos, os informantes não quiseram fornecer detalhes, argumentam apenas que os assassinos "chegam ao local, cometem o crime e fogem".

Questionados a respeito das diferenças da criminalidade no meio rural na atualidade, os entrevistados apontam o consumo de drogas e o narcotráfico, principalmente o envolvimento da juventude (GIDDENS, 2008), que se desloca para as zonas rurais para cometer roubos e furtos com vistas ao pagamento de dívidas. Tanto os entrevistados quanto os conteúdos das entrevistas apontam para a associação entre os criminosos.

Nas narrativas dos entrevistados ficou clara a opinião de que o rural vem deixando de ser considerado um lugar pacífico e começa a ser equiparado aos centros urbanos no que diz respeito às ações criminosas.

Agora na zona rural está ficando mais perigoso, mas é para todo lugar, né, roubam direto por aqui, moto, casa..., mas hoje né, cidade grande com cidade pequena, está tudo a mesma coisa né, droga está para todo lado (E8).

Hoje a roça está ficando a mesma coisa que na cidade, está tendo roubo, assalto na zona rural também (E11). 
Antigamente as pessoas dormiam com janela aberta, o pão e o leite era deixado nas portas das casas, isso desapareceu (E2).

Essas observações se opõem a alguns estudos, como o de Carneiro (2007, p.64), que apresentam o espaço rural como "lugar parado" e atrativo para populações citadinas, que buscam nessas localidades a segurança e a tranquilidade não vivenciadas nos espaços urbanos, principalmente nas grandes metrópoles.

Na mesma linha de raciocínio, Gislene Silva (2009) analisa as representações e imaginários de leitores urbanos da revista "Globo Rural" sobre o projeto futuro de viver no meio rural e ter uma "casa no campo". Conforme abordado pela autora, o rural é caracterizado pela população citadina como lugar de cura, de solidariedade, de bem-estar, onde a criminalidade e a violência ainda não se instalaram. Essas características contrastam com o teor das reportagens divulgadas pelos veículos de comunicação aqui analisados e pelas narrativas dos entrevistados, pois para eles o "sossego acabou".

Para além do narcotráfico e do consumo de drogas, os entrevistados associam a perda da tranquilidade no campo e o aumento do número de crimes com a ineficiência da segurança pública em seus municípios. Argumentam sobre a ausência de postos policias nas proximidades, o que dificulta a proteção das pessoas e a captura dos criminosos.

\footnotetext{
Eles (os criminosos) acham que podem fazer de tudo, porque até vir uma polícia da cidade de São Geraldo, Coimbra, Paula Candido, ou de outro lugar ... eles pensam posso roubar uma moto, qualquer coisa aqui, porque até eles chegar ... a polícia está chegando aqui, eles já estão lá em Nova Viçosa (E3).

A gente não vê polícia. Esses dias a gente falou para eles que a gente paga nossos impostos e a gente não vê uma viatura por aqui. Aqui é próximo da cidade e quando roubam aqui eles não esquentam muito. A gente vê passando polícia de outros lugares aqui na estrada, mas a do Município não dá assistência aqui. Eles falam que não tá vindo dinheiro (E4).
}

Neste mesmo sentido, os entrevistados apontam o armamento como alternativa à ineficiência da segurança pública. A sensação de insegurança vem favorecendo, segundo os entrevistados, a defesa da posse de arma de fogo. Um deles argumenta que com a vitória de Jair Bolsonaro a população irá receber uma arma de fogo e uma caixa de munição para se proteger. Contudo, conforme divulgado nos veículos de comunicação, parte da população possui posicionamento contrário e critica o armamento, afirmando que a segurança pública é dever do Estado garantido pelos princípios constitucionais. Ao armar o cidadão, tal responsabilidade é retirada paulatinamente do ente público e colocada nas mãos dos indivíduos.

Por meio das narrativas também fica evidente que o crescimento da criminalidade vem alterando as práticas cotidianas. Os entrevistados afirmam não poderem mais caminhar à noite, dormir sozinhos em suas propriedades, deixar utensílios da cozinha pendurados no fogão a lenha do lado de fora da casa. Um deles afirma que em outras épocas não havia problema "nem de dormir na rua" e hoje corre-se o risco de ser 
"assaltado e queimado por criminosos". Outro alega que antigamente deixava o portão aberto e que atualmente isso é impossível de acontecer:

Nem tá podendo andar na rua mais não, não pode ficar sozinho também não (E11).

Antigamente eu tinha o costume de sair e deixar o portão aberto, hoje em dia não deixo não, tá ficando bem perigoso, a zona rural para mim tá bem mais violenta (E7).

Antigamente as coisas pareciam ser mais simples. A movimentação era menor. Não existiam assaltos mesmo, existiam roubos (E3)

Essas mudanças ocasionadas como consequências da criminalidade fazem com que os cotidianos se modifiquem e algumas atividades sejam alteradas. Tal consideração vem ao encontro do que afirma Baierl (2008, p.146) em seu estudo sobre como a violência se expressa nas cidades. A autora demonstra que a violência vem alterando a arquitetura das casas e dos comércios e os habitantes mudam seus trajetos e as formas de interação social:

O medo de ser assaltado ou roubado em casa, no portão, no farol, vem levando esses personagens a alterarem significativamente suas rotinas e ritmos diários: horários de sair e chegar, evitando circular ou transitar à noite pelas ruas e sozinhos (BAIERL, 2008, p.146).

Essas alterações também podem ser verificadas no meio rural e, durante as entrevistas, um dos participantes mostrou uma fotografia da fachada de sua propriedade antes de ter ocorrido um roubo e pediu para que fosse fotografada na atualidade, para mostrar as modificações realizadas para aumentar a segurança (Figura 1).

Figura 1. Entrada da propriedade rural antes e depois de ser roubada. Fonte: Autores 2019.
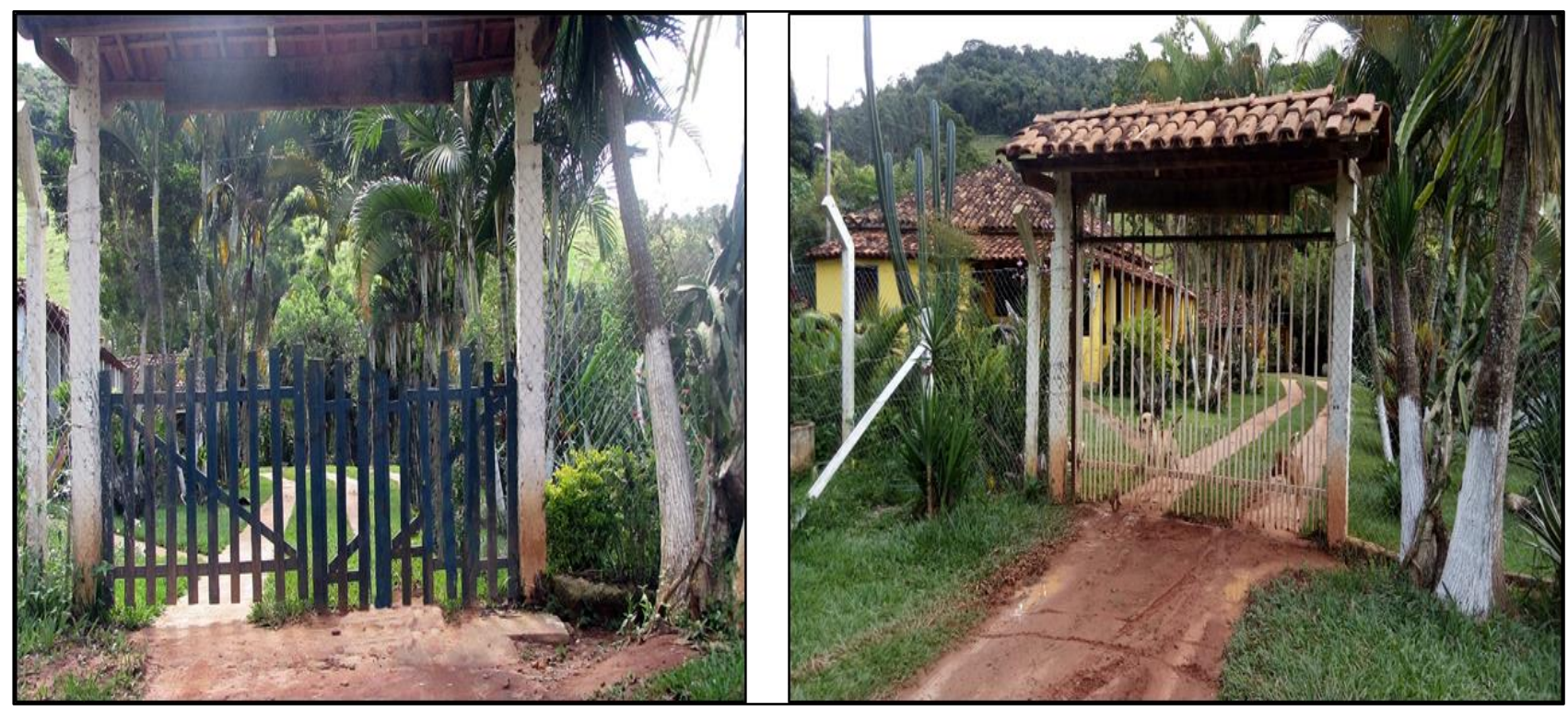
Finalmente, cabe destacar que a percepção do aumento da violência e da criminalidade podem alterar os projetos familiares de deslocamento espacial e abandono das propriedades rurais. Conforme analisam Andrade e Diniz (2013), a criminalidade se expande nos centros urbanos, mas também atinge pequenos municípios e zonas rurais, e começa a se consolidar como um dos principais fatores a contribuir para amplificação das migrações em determinadas regiões (ANDRADE E DINIZ, 2013).

Dentre as opções que o pequeno produtor possui - investir em sistemas de segurança eletrônicos, contratar empresas de segurança privada para proteger a propriedade ou mesmo investir na compra ilícita de armamento -, a mais viável, segundo os entrevistados, é a venda da propriedade e a busca de uma vida melhor nos centros urbanos.

\footnotetext{
Antigamente não tinha isso não, muita gente de sitiozinho pequeno está indo morar na cidade, porque é mais fácil [o criminoso] entrar na sua casa na roça que na cidade, porque tem mais gente para ver ... está ficando bem perigoso, a zona rural para mim tá bem mais violenta hoje (E7).

A vida no campo não é fácil, nunca foi fácil, acho que tão cedo não será fácil. Se a gente perder a segurança, se a gente perder a tranquilidade que a roça sempre teve, muita gente vai acabar desistindo disso né, como já vem desistindo por falta de políticas públicas que favorecem o pequeno produtor, o pequeno criador de animais, então a gente precisa de políticas públicas e de segurança também para que incentive o morador da zona rural a continuar lá, então eu acho que se você não tem isso a tendência é sempre todo mundo migrar para cidade e dar o espaço da zona rural para grandes produtores (E1).
}

Os entrevistados mais velhos, particularmente os aposentados, relatam não possuírem condições financeiras de manter uma vida na cidade e, por isso, não abandonariam suas propriedades para viverem de aluguel. É importante ressaltar que há uma dualidade na percepção dos entrevistados quanto ao futuro no campo ou nas cidades. Alguns argumentam que mesmo o campo não sendo "como antigamente", acreditam que ainda seja mais tranquilo e menos violento que as cidades. Já outros argumentam que o campo está muito pior e justificam tal posição em função da falta de segurança pública, das amplas possibilidades de fuga facilitadas pela baixa densidade populacional e isolamento das estradas, dificuldades em pedidos de socorro e a perseguição e localização dos criminosos.

\section{CONCLUSÕES}

Os dados apresentados sobre a criminalidade no campo contribuem para repensar o rural brasileiro, que vem passando por um processo de ressignificação e se equiparando aos centros urbanos e grandes metrópoles quando o assunto é segurança pública. Esse fato também vem se incorporando ao senso comum da população que trabalha ou reside em espaços rurais.

A inexistência de política de segurança pública para o campo coloca a população rural em situação de vulnerabilidade, o que muitas vezes contribui para o enfrentamento direto entre os agricultores e os 
criminosos. Dessa forma, viver no campo no cenário atual torna-se um fator de risco não somente para os pequenos proprietários, trabalhadores e moradores rurais de baixa renda, como acarreta também uma ameaça para todo o setor produtivo do agronegócio brasileiro, embora os grandes proprietários disponham de recursos diferenciados para garantir segurança.

A análise das reportagens jornalísticas de veículos de circulação local e regional, bem como das entrevistas com pequenos proprietários rurais, aponta que há uma percepção sobre o papel do narcotráfico e dos mercados ilegais no aumento da criminalidade no espaço rural, atribuindo-se aos jovens o protagonismo dos atos de roubo e furto, cujos índices são crescentes em todo o estado de Minas Gerais e também na Zona da Mata.

O fato de os entrevistados afirmarem conhecer pessoas próximas ou eles próprios terem sido vítimas da criminalidade corrobora a representação negativa que vem sendo elaborada para o espaço rural, representação essa também disseminada pelas mídias. Assim, no caso desta pesquisa, apesar do pequeno número de entrevistados, pode-se afirmar que a ressignificação do rural é influenciada pelos discursos circulantes nos meios de comunicação e também pelas experiências individuais e coletivas vividas no cotidiano e relatadas nos momentos de interação social.

É importante destacar a falta de estudos científicos que relacione as falhas no processo de desenvolvimento rural, o aumento recente da criminalidade no campo e, consequentemente, o abandono das propriedades. Durante décadas a sociologia ocupou-se de investigar o crime no cenário urbano, mas na conjuntura atual faz-se necessário este ramo de estudo debruçar-se sobre as novas configurações dos crimes e sua inserção nas comunidades rurais.

\section{AGRADECIMENTOS}

A FAPEMIG pelo financiamento do projeto e ao CNPq pela concessão da bolsa de pós-graduação.

\section{REFERÊNCIAS}

ANDRADE, L. T. D.; DINIZ, A. M. A. A reorganização espacial dos homicídios no Brasil e a tese da interiorização. Revista Brasileira de Estudos de População, Rio de Janeiro, v. 30, p. 171-192, 2013.

BAIERL, L. F. Medo Social: dilemas cotidianos. Ponto-e-vírgula, 3: 138-151, 2008.

CARNEIRO, M. J. Juventude e novas mentalidades no cenário rural. In: CARNEIRO, M. J.; CASTRO, E. G. Juventude Rural em perspectiva. Rio de Janeiro, Mauad X, 2007. $311 \mathrm{p}$.

BRASIL. Lei n. 2.848, 7 de dezembro de 1940. Institui o Código Penal. Diário Oficial da União, Brasília, DF, 7 dez. 1940. Disponível em: $<$ http://www.planalto.gov.br/ccivil 03/decreto-lei/del2848compilado.htm> Acesso em: 09 abr. 2019. 
CNA. CONFEDERAÇÃO DA AGRICULTURA E PECUÁRIA DO BRASIL. Observatório da Criminalidade no Campo. 2017. Disponível em: $<w w w . c n a b r a s i l . o r g . b r>$. Acesso em: 17 abr. 2019.

COMISSÃO PASTORAL DA TERRA. Massacres no Campo, 2017. Disponivel em: <https://www.cptnacional.org.br/>. Acesso em: 15 jan. 2019.

DE QUEIROZ, M. I. P. o mandonismo local na vida política brasileira e outros ensaios. 1a. ed. São Paulo: Editora Alfa-Omega, v. 5, 1976.

DEL PRIORE, M.; VENÂNCIO, R. Uma história da vida rural no Brasil. Rio de Janeiro: Ediouro, 2006. 223 p.

FELIX, S. A. Geografia do crime: interdisciplinaridade e relevâncias. Marília-SP: Unesp Publicações, 2002.

FERRAZ, A.; BERALDO, P. "Segurança vira demanda de ruralistas na eleição", o Estado de São Paulo, São Paulo, 6 de maio de 2018.

FRANCO, M. S. D. C. O código do sertão. In: Homens livres na ordem escravocrata. 3ạ Edição. ed. São Paulo: Kairós, 1983. Cap. 1.

GIDDENS, A. Sociologia. Tradução de Alexandra Figueiredo; Ana Patrícia Duarte Baltazar, et al. 6ạ. ed. Lisboa: Fundação Calouste Gulbenkian, 2008.

GUIMARÃES, A. P. As classes perigosas: banditismo urbano e rural. Rio de Janeiro: Edições Graal, v. 11, 1981.

HOBSBAW, E. J. Bandidos. Tradução de Donaldson Magalhães Garschagen. 2ạ. ed. Rio de Janeiro: Forense Universitária, 1976.

MARCONI, M. D. A.; LAKATOS, E. M. Fundamentos de metodologia científica. 5a.. ed. São Paulo: Atlas S.A, 2003.

MÉLO, J. L. B. D. O "velho" e o "novo" da violência rural na froteira Brasil - Uruguay. Sociedade e Estado, Brasília, v. 19, p. 121-150, jan./jun. 2004.

PIMENTA, M. D. M. Masculinidades e sociabilidades: Compreendendo o envolvimento de jovens com a violência e criminalidade. DILEMAS: Revista de Estudos de Conflito e Controle Social, Rio de Janeiro, v. 7, p. 701-730, Jul/Ago/Set 2014.

SAPORI, L. F.; SOARES, G. A. D. Por que cresce a violência no Brasil? 1a. ed. Belo Horizonte: autêntica, 2015.

SILVA, G. O sonho da casa no campo: jornalismo e imaginário de leitores urbanos. Florianópolis: Insular, 2009.

ZALUAR, A.; NORONHA, J. C. \& ALBUQUerque, C. Violência: Pobreza ou Fraqueza Institucional? Cad. Saúde Públ., Rio de Janeiro, 10 (suplemento 1): 213-217, 1994. 